\title{
A specific role for $\mathrm{Ca}^{2+}$ in the oxidation of exogenous $\mathrm{NADH}$ by Jerusalem-artichoke (Helianthus tuberosus) mitochondria
}

\author{
Ian M. MØLLER, Sally P. JOHNSTON and John M. PALMER \\ Department of Botany, Imperial College of Science and Technology, Prince Consort Road, \\ London SW7 2BB, U.K.
}

(Received 18 July 1980/Accepted 22 September 1980)

\begin{abstract}
1. The addition of chelators to a suspension of mitochondria in a low-cation medium containing 9-aminoacridine caused a decrease in 9-aminoacridine fluorescence. The chelators removed bivalent cations from the membranes and allowed more 9aminoacridine to move into the diffuse layer. The relative effect of EGTA and EDTA on the fluorescence suggested that the mitochondria are isolated with about equal amounts of $\mathrm{Ca}^{2+}$ and $\mathrm{Mg}^{2+}$ on the membranes. 2. The removal of the bivalent ions by chelators resulted in the inhibition of NADH oxidation. The inhibition could not be removed by adding sufficient decamethylenebistrimethylammonium ion $\left(\mathrm{DM}^{2+}\right)$ to screen the fixed charges on the membranes and restore the fluorescence of 9-aminoacridine. This observation suggests that bivalent metal ions have a specific role in the oxidation of NADH. 3. $\mathrm{Ca}^{2+}$ and not $\mathrm{Mg}^{2+}$ reversed the inhibition of NADH oxidation caused by EGTA, whereas both reversed the inhibition caused by EDTA. This suggests that $\mathrm{Ca}^{2+}$ plays a specific role and that $\mathrm{Mg}^{2+}$ reverses the inhibition caused by EDTA by displacing the bound calcium from the chelator. 4. The results are interpreted as showing that $\mathrm{Ca}^{2+}$ plays a specific role in the oxidation of external NADH in addition to its ability to screen electrostatically or bind to the fixed charges associated with the surface of the membrane.
\end{abstract}

In a previous paper (Johnston et al., 1979) it was shown that cations enhanced, unspecifically, the oxidation of exogenous NADH by Jerusalem-artichoke (Helianthus tuberosus) mitochondria. This enhancement was closely correlated with the ability of the cations to release the quenched fluorescence of 9-aminoacridine. The non-specificity of the cations and the relative effectiveness of cations of different valencies $\left(\mathrm{C}^{3+}>\mathrm{C}^{2+}>\mathrm{C}^{+}\right)$was consistent with the view that they acted by screening the fixed charges associated with the surface of the membranes. The screening would decrease the repulsion of the negatively charged substrate, NADH, and thus cause an increase in the effective substrate concentration near the active site of the membranebound NADH dehydrogenase (Johnston et al., 1979).

Abbreviations used: (DM) $\mathrm{Br}_{2}$, decamethylene-1,10bistrimethylammonium bromide; $\mathrm{DM}^{2+}$, the cation formed by the dissociation of (DM) $\mathrm{Br}_{2} ;(\mathrm{TEC}) \mathrm{Cl}_{3}$, tris(ethylenediamine)cobalt(III) chloride: $\mathrm{TEC}^{3+}$, the cation formed by the dissociation of (TEC)Cl ${ }_{3}$; Tes, $2-\{[2-$ hydroxy - 1,1 - bis(hydroxymethyl)ethyllamino \}ethanesul phonic acid.
In previous publications it has been proposed that $\mathrm{Ca}^{2+}$ is specifically involved in the oxidation of exogenous NADH by both Jerusalem artichoke (Coleman \& Palmer, 1971; Cowley \& Palmer, 1978) and maize (Zea mays) (Miller et al., 1970; Earnshaw, 1975) mitochondria. In Jerusalem artichoke the apparent requirement for $\mathrm{Ca}^{2+}$ has only been observed in the presence of chelators like EGTA (Coleman \& Palmer, 1971) and citrate (Cowley \& Palmer, 1978). In maize, $\mathrm{Ca}^{2+}, \mathrm{Ba}^{2+}$ and $\mathrm{Sr}^{2+}$ were the only bivalent cations causing a stimulation of NADH oxidation when the mitochondria were suspended in a $0.2 \mathrm{M}-\mathrm{KCl}$ medium in the absence of chelators (Miller et al., 1970). However, no attempt was made in these investigations to distinguish between general screening of negative charges on the membrane surface (Johnston et al., 1979) and more specific effects of the cations which stimulate NADH oxidation.

In the present investigation it is found that Jerusalem-artichoke mitochondria are isolated with a complement of both $\mathrm{Ca}^{2+}$ and $\mathrm{Mg}^{2+}$ on the membranes. When chelators are used to remove these bivalent cations an inhibition is observed even 
under conditions where the 9-aminoacridine fluorescence indicates that screening is maximal. This points to a specific effect of either $\mathrm{Ca}^{2+}$ or $\mathrm{Mg}^{2+}$, and it is shown that NADH oxidation specifically requires $\mathrm{Ca}^{2+}$ for activity. However, the $\mathrm{Mg}^{2+}$ on the membranes does seem to have a small and yet, unexplained, effect on NADH oxidation. Under certain conditions non-linear rates are observed, and this phenomenon will be discussed with respect to a possible reaction mechanism.

\section{Materials and methods}

\section{Preparation of mitochondria}

Mitochondria were prepared from Jerusalemartichoke (Helianthus tuberosus) tubers bought in the market and stored at $4^{\circ} \mathrm{C}$ until used. The procedure was essentially that of Palmer \& Kirk (1974) with the following modifications. The first centrifugation was at $48000 \mathrm{~g}$ for $2 \mathrm{~min}$. The pellets were resuspended in $0.4 \mathrm{M}$-sucrose $/ 5 \mathrm{mM}$-Tes $(\mathrm{pH} 7.2) / 0.1 \%(\mathrm{w} / \mathrm{v})$ bovine serum albumin and, after a short centrifugation (accelerating to $12000 \mathrm{~g}$ followed by immediate deceleration in a Sorvall RC-2B centrifuge with an SS-34 rotor) after which the pellets were discarded, the mitochondria were recovered from the supernatant by centrifugation at $48000 \mathrm{~g}$ for $2 \mathrm{~min}$. These mitochondria were washed a second time in $0.4 \mathrm{M}$-sucrose $/ 2 \mathrm{mM}$-Tes (potassium salt) $(\mathrm{pH} 7.2) / 0.1 \%(\mathrm{w} / \mathrm{v})$ bovine serum albumin to minimize the number of cations present in the final preparation. The specific activity of the final preparation, with respect to oxygen uptake, could not be significantly increased by further purification on a density gradient, showing that the preparation was not extensively contaminated with other organelles.

\section{Measurement of NADH oxidation}

The oxidation of exogenous NADH was measured as $\mathrm{O}_{2}$ consumption in a Rank Brothers oxygen electrode (total volume $1.0 \mathrm{ml}$ ) at $25^{\circ} \mathrm{C}$ in a low-cation medium consisting of $0.3 \mathrm{M}$-sucrose/ $5 \mathrm{~mm}$-Tes (potassium salt) and $200 \mathrm{nM}$-carbonyl cyanide $p$-trifluoromethoxyphenylhydrazone at $\mathrm{pH}$ 7.2. After the addition of mitochondria, a small amount of NADH $(10-40 \mu \mathrm{M})$ was added and this was allowed to be completely oxidized before the main addition of NADH ( $1 \mathrm{mM})$ was made. The reason for the use of this initial 'sparker' NADH is discussed in the first part of the Results section.

When chelators were used, these were added after the sparker NADH had been completely oxidized and $30 \mathrm{~s}$ before the main addition of NADH. $(\mathrm{DM}) \mathrm{Br}_{2}$ was added concomitant with the main addition of NADH.

\section{Fluorescence of 9-aminoacridine}

The fluorescence of 9-aminoacridine was measured as described by Johnston et al. (1979).

\section{Determination of protein concentration}

Protein concentration was determined by the method of Lowry et al. (1951) after solubilizing the mitochondria with $0.5 \%(\mathrm{w} / \mathrm{v})$ deoxycholate. Bovine serum albumin (Sigma no. A-8022) was used as the standard.

\section{Chemicals}

9-Aminoacridine was from Koch-Light Laboratories (Colnbrook, Bucks., U.K.). (TEC) $\mathrm{Cl}_{3}$ was obtained from Alfa Products, U.S.A. (distributed by Lancaster Synthesis, Lancaster, U.K.). All other chemicals were of analytical grade and were supplied by BDH or Sigma, both of Poole, Dorset, U.K.

\section{Results}

Use of 'sparker' $\mathrm{NADH}$

When the oxidation of exogenous NADH by Jerusalem-artichoke mitochondria was measured as described by Johnston et al. (1979), it was observed that the lag before a maximal linear oxidation rate was reached was longer in the presence of low concentrations of cations than it was in the presence of higher concentrations of cations. This is shown in Figs. $1(b)$ and $1(d)$. All cations tested were equally effective in shortening the time necessary to reach the maximal linear rate of NADH oxidation. In an attempt to decrease the duration of the lag in NADH oxidation, a low concentration of NADH was allowed to be completely oxidized in order to achieve a priming effect before the main addition of NADH was made. This small initial addition will hereafter be referred to as a 'sparker'. Results presented in Figs. $1(a)$ and $1(b)$ show that the lag in oxidation was decreased from 90 to $55 \mathrm{~s}$ when a sparker addition of $\mathrm{NADH}$ was used in the low-cation medium and from 60 to $30 \mathrm{~s}$ in the presence of $2 \mathrm{mM}-(\mathrm{DM}) \mathrm{Br}_{2}$ (Figs. $1 c$ and $1 d$ ). The duration of the lag and the effect of the sparker NADH appeared to vary with the age of the tubers (results not shown). To decrease such variability in the assays, to have consistent assay conditions and to shorten the lag in obtaining maximal linear rates of $\mathrm{NADH}$ oxidation, sparker NADH was used in all experiments.

\section{Sequence of addition of chelator and main NADH}

Both Earnshaw (1975) and Cowley \& Palmer (1978) have reported that chelators added after NADH cause less inhibition than an equal amount added before NADH. Since EGTA and EDTA were to be used extensively in the present investigation the effect of sequence of addition was characterized in a series of experiments. The results are shown in Table 1 and Fig. 2.

In a low-cation medium (total cation concen- 


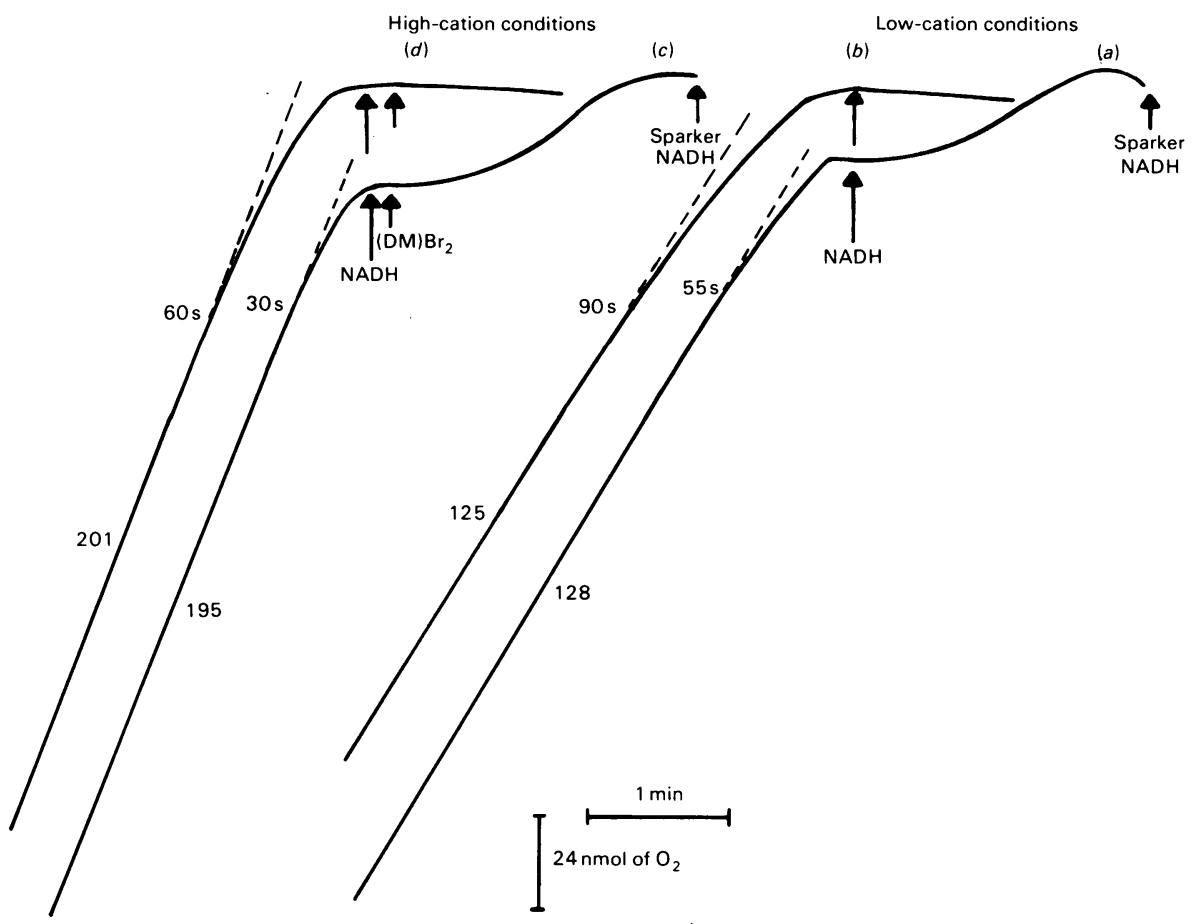

Fig. 1. Effect of sparker NADH on the lag in attaining maximal linear rates of NADH oxidation NADH oxidation was measured as described in the Materials and methods section. Additions were made as indicated on the traces, and final concentrations were: $40 \mu \mathrm{M}$-sparker NADH ( $a$ and $c$ ), $2 \mathrm{mM}-(\mathrm{DM}) \mathrm{Br}_{2}(c$ and $d)$, $1 \mathrm{mM}-\mathrm{NADH}$ and $0.48 \mathrm{mg}$ of mitochondrial protein $\cdot \mathrm{ml}^{-1}$. The numbers on the traces are rates of NADH oxidation in $\mathrm{nmol}$ of $\mathrm{O}_{2} \cdot \mathrm{min}^{-1} \cdot \mathrm{mg}^{-1}$. The broken lines indicate where linearity was attained, and the duration of the lag is given.

Table 1. Effect of sequence of addition of chelator and main NADH on the oxidation of NADH NADH oxidation was measured as described in the Materials and methods section $\left(0.48 \mathrm{mg}\right.$ of protein $\left.\cdot \mathrm{ml}^{-1}\right)$ and chelator was added either 30 s before the main NADH addition $\left[ \pm(\mathrm{DM}) \mathrm{Br}_{2}\right]$ or after the main NADH addition at $65 \% \mathrm{O}_{2}$ when the rate of oxidation was linear. Rates $\left(\mathrm{nmol}\right.$ of $\left.\mathrm{O}_{2} \cdot \mathrm{min}^{-1} \cdot \mathrm{mg}^{-1}\right)$ are given as means \pm S.D. $(n=$ number of measurements on one preparation of mitochondria).

\section{Additions}

Controls

$200 \mu$ M-EGTA

(a) Before main NADH

(b) After main NADH

$200 \mu \mathrm{M}$-EDTA

(a) Before main NADH

(b) After main NADH
Rate in lowcation medium

$$
122 \pm 8(7)
$$$$
\begin{gathered}
62 \pm 2(2) \\
105 \pm 7(2)^{*}
\end{gathered}
$$

$$
49 \pm 6(2)
$$$$
94 \pm 2(2)^{*}
$$

Inhibition

(\%)

$$
-
$$

49

16

60

18
Rate in low-

$\begin{array}{cc}\text { cation medium } & \text { Inhibition } \\ +2 \mathrm{mM}-(\mathrm{DM}) \mathrm{Br}_{2} & (\%)\end{array}$

$$
192 \pm 8(4)
$$

$$
60 \pm 11(2)
$$

Curvilinear

(see Fig. 2)

$$
\begin{array}{r}
28 \pm 6(2) \\
\text { Curvilinear } \\
\text { (see Fig. 2) }
\end{array}
$$

${ }^{*}$ Rates measured 1 min after addition of chelator.

tration about $3 \mathrm{mM}-\mathrm{K}^{+}$), both chelators caused a much greater inhibition if added before the NADH (Table 1). When chelators were added before $\mathrm{NADH}$, the rate steadily increased over a period of minutes (the duration was apparently dependent on the final rate) to give ultimately a maximal linear rate. This linear rate is the rate used to quantify the effect of chelators. Chelators added after NADH in 


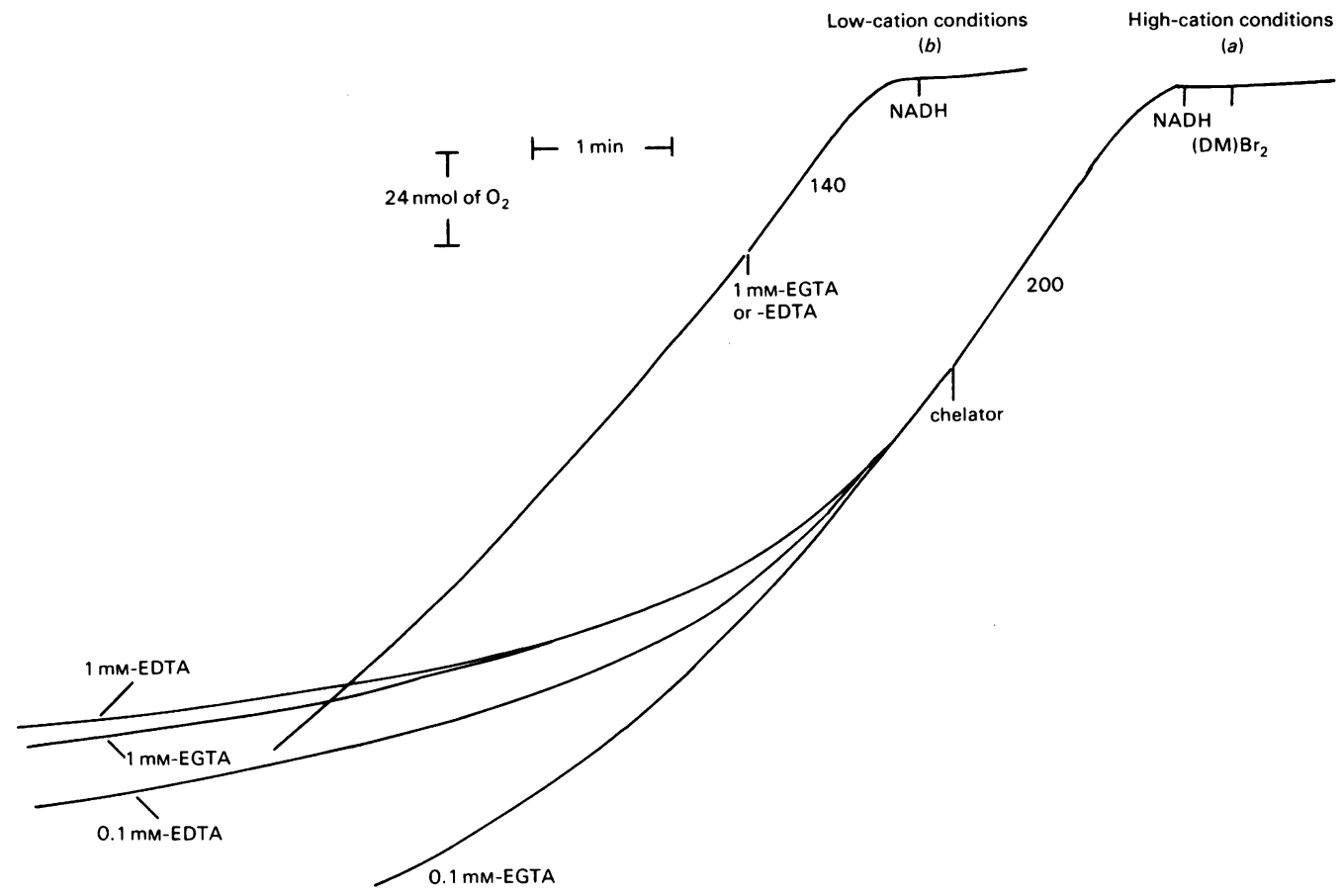

Fig. 2. Effect of chelators on NADH oxidation when added during oxidation

NADH oxidation was measured as described in the Materials and methods section and additions were made as indicated on the traces. Numbers on the traces are NADH oxidation in $\mathrm{nmol}$ of $\mathrm{O}_{2} \cdot \mathrm{min}^{-1} \cdot \mathrm{mg}^{-1}$. Protein concentrations were $0.28 \mathrm{mg} \cdot \mathrm{ml}^{-1}$ in $(a)$ and $0.46 \mathrm{mg} \cdot \mathrm{ml}^{-1}$ in $(b)$.

the low-cation medium caused an instant small inhibition that seemed to increase slowly with time (Fig. 2b).

When $\mathrm{DM}^{2+}$ was added to the low-cation medium, the rate of NADH oxidation increased by $57 \%$ (Table 1), confirming previous observations (Johnston et al., 1979). DM ${ }^{2+}$ was used to obtain maximal screening conditions without interfering with the chelators by binding them (Møller et al., 1980). In the presence of $\mathrm{DM}^{2+}$ the chelators were more effective in inhibiting the oxidation of NADH (Table 1 and Fig. 2), but again an effect of sequence of addition was observed. Linear rates were reached if chelators were added before NADH. When added after NADH, chelators caused an inhibition that increased rapidly with time. The extent of this inhibition and the rate at which it became effective was dependent on the concentration of the chelator (Fig. $2 a$ ).

To avoid the problems of curvilinear rates, chelators were subsequently added $30 \mathrm{~s}$ before the addition of the main NADH.

The effect of chelators on NADH oxidation and on the fluorescence of 9-aminoacridine

In Table 1 and Fig. 2, EDTA was shown to cause

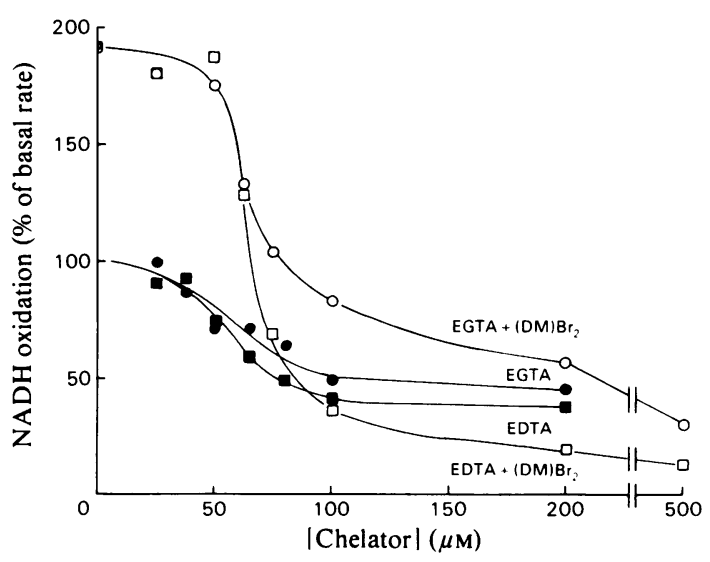

Fig. 3. Effect of concentration of chelators on the oxidation of $\mathrm{NADH}$ under low-cation and high-cation conditions

NADH oxidation was measured on two preparations of mitochondria as described in the Materials and methods section, with either $0.52 \mathrm{mg}$ (low-cation medium) or $0.44 \mathrm{mg}$ of mitochondrial protein $/ \mathrm{ml}\left[+(\mathrm{DM}) \mathrm{Br}_{2} \mid\right.$. The rates are expressed as percentages of the rate in the low-cation medium in the absence of chelators (122 and $148 \mathrm{nmol}$ of $\mathrm{O}_{2} \cdot \mathrm{min}^{-1} \cdot \mathrm{mg}^{-1}$ for the two preparations). 
a significantly greater inhibition than EGTA. This is confirmed in Fig. 3, in which the effect of increasing concentrations of chelators on NADH oxidation is shown. Both chelators gave rise to S-shaped inhibition curves under conditions where screening would be expected to be near maximum $[+2 \mathrm{mM}$ (DM) $\mathrm{Br}_{2}$ ] as well as in the low-cation medium alone. Both EGTA and EDTA cause equal inhibition of NADH oxidation below $50 \mu \mathrm{M}$, whereas above this concentration EDTA proved more effective (Fig. 3). In the low-cation medium, inhibition by $100 \mu \mathrm{M}$ EDTA was $57 \%$, which was $14 \pm 5 \%$ (mean \pm S.D., $n=$ six preparations) more than that by $100 \mu \mathrm{M}$ EGTA. Similarly, EDTA inhibited $23 \pm 5 \%(n=5)$ more than EGTA in the presence of $(\mathrm{DM})^{2+}(81$ as against 57\%).

$\mathrm{DM}^{2+}$ has until now been assumed to give nearmaximal screening conditions, even in the presence of chelators. That this is the case is shown in Fig. 4, where the fluorescence of 9-aminoacridine is measured at various concentrations of chelators either in a low-cation medium $[2 \mathrm{mM}$-Tes (potassium salt)] or in the presence of $2 \mathrm{mM}-\mathrm{DM}^{2+},-\mathrm{Mg}^{2+}$ or $-\mathrm{Ca}^{2+}$. The addition of mitochondria to 9-aminoacridine in the low-cation medium caused a decrease in fluorescence from approx. 17 to 10 in arbitrary units (results not shown). This indicates that 9-aminoacridine, which is a univalent cation, was being concentrated in the diffuse layer adjacent to

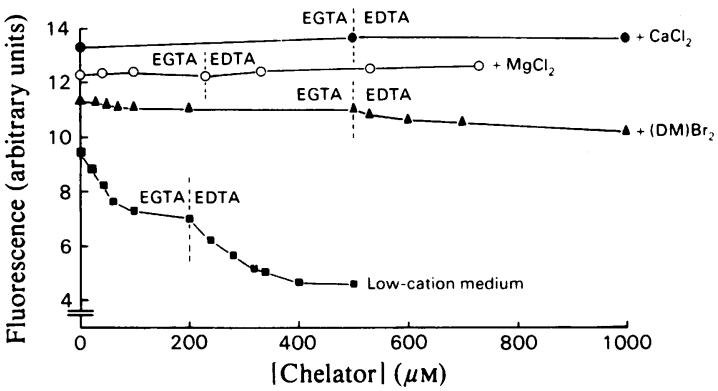

Fig. 4. Sensitivity of the fluorescence of 9-aminoacridine to chelators in the presence of bivalent cations

The fluorescence of 9-aminoacridine was measured as described in the Materials and methods section, either in the absence of any added cations (cation concentration about $1 \mathrm{mM}-\mathrm{K}^{+}$) or in the presence of $2 \mathrm{mM}-(\mathrm{DM}) \mathrm{Br}_{2},-\mathrm{MgCl}_{2}$ or $-\mathrm{CaCl}_{2}$ as indicated on the Figure. The results are from two preparations of mitochondria and the results in the low-cation medium were nearly identical. Protein concentrations were $0.52 \mathrm{mg} \cdot \mathrm{ml}^{-1}\left[(\mathrm{DM}) \mathrm{Br}_{2}\right.$ and $\left.\mathrm{CaCl}_{2}\right]$ and $0.46 \mathrm{mg} \cdot \mathrm{ml}^{-1}\left(\mathrm{MgCl}_{2}\right)$. Maximum release of fluorescence quenching was achieved by adding $33 \mathrm{mM}-\mathrm{MgCl}_{2}$ and the amount of fluorescence was just above that reached with $2 \mathrm{~mm}-\mathrm{CaCl}_{2}$. the negatively charged membranes of the mitochondria. The addition of EGTA caused a further decrease in fluorescence, and EDTA had an additional effect when added after EGTA (Fig. 4). EDTA alone had the same effect on fluorescence as EGTA followed by EDTA (results not shown). This difference in effect on 9-aminoacridine fluorescence between the two chelators will be discussed below.

The addition of bivalent cations to a mitochondrial suspension containing 9-aminoacridine caused a marked increase in fluorescence (Fig. 4), $\mathrm{DM}^{2+}$ being less effective than the bivalent-metal cations. The increase in fluorescence shows that the screening of the charges on the membranes was made more efficient by the bivalent cations causing a release of 9-aminoacridine into solution. Chelators had no effect on the fluorescence of 9-aminoacridine in the presence of $\mathrm{Ca}^{2+}$ or $\mathrm{Mg}^{2+}$ and only a small decrease was observed in the presence of $\mathrm{DM}^{2+}$, indicating that a high degree of screening of fixed charges was maintained in all cases (Fig. 4).

The results presented so far show that chelators inhibit NADH oxidation (Table 1, Figs. 2 and 3), even under conditions where the fixed charges were fully screened (Figs. 3 and 4). Thus chelators have a role in causing the inhibition of oxidation of NADH in addition to the de-screening of fixed membrane charges.

\section{The role of $\mathrm{Ca}^{2+}$ and $\mathrm{Mg}^{2+}$ bound to the membranes}

The inhibitory effect of the chelators may be due to the removal of bivalent cations, specifically required for $\mathrm{NADH}$ oxidation, from the membranes of the mitochondria. Since EDTA binds $\mathrm{Mg}^{2+}$ better than EGTA does, although they complex $\mathrm{Ca}^{2+}$ equally well (Sillén \& Martell, 1964, 1971), the relative efficiencies of the two chelators in causing a decrease in the fluorescence of 9-aminoacridine in the low-cation medium (Fig. 4) would seem to indicate that the mitochondria are isolated with a complement of about equal amounts of $\mathrm{Ca}^{2+}$ and $\mathrm{Mg}^{2+}$ on the membranes.

In Fig. 5 the effect of chelators on the fluorescence of 9-aminoacridine in a normal preparation of mitochondria is compared with that in mitochondria washed with EGTA $+\mathrm{Mg}^{2+}$ as described in the legend. This treatment would be expected to remove $\mathrm{Ca}^{2+}$ from the membranes and substitute it with $\mathrm{Mg}^{2+}$, thus leaving the membranes relatively depleted of $\mathrm{Ca}^{2+}$ and enriched with $\mathrm{Mg}^{2+}$. The fluorescence of 9-aminoacridine in the presence of the control mitochondria shows a response to chelators very similar to that found in Fig. 4 [(fluorescence decrease with EGTA)/(fluorescence decrease with EDTA) $=0.60$ l. The treated mitochondria, on the other hand, show a much decreased response to EGTA and an increased response to 


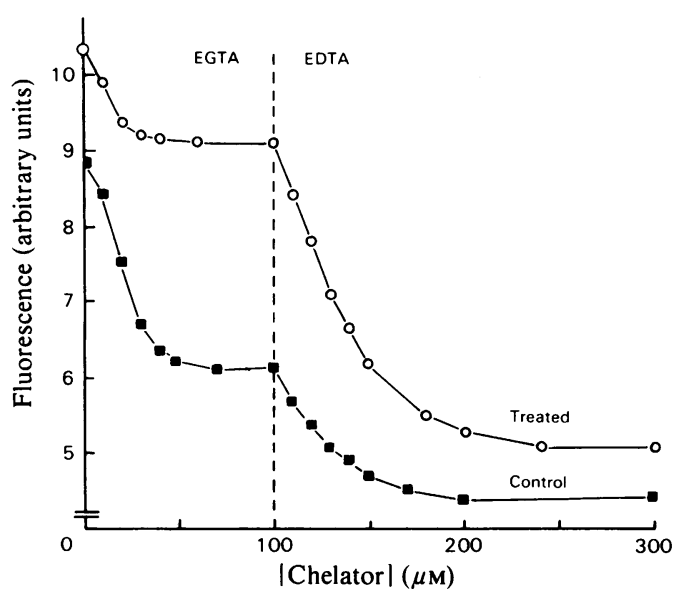

Fig. 5. Effect of chelators on the fluorescence of 9-aminoacridine in a suspension of control mitochondria and mitochondria washed with EGTA $+M g^{2+}$

The pellets from the first centrifugation of an ordinary preparation (see the Materials and methods section) were divided into halves. One half was treated as described in the Materials and methods section. The other half was resuspended in $0.3 \mathrm{M}$-sucrose $/ 5 \mathrm{~mm}$-Tes $/ 2.5 \mathrm{~mm}-\mathrm{MgCl}_{2} / 1 \mathrm{~mm}$-EGTA, $\mathrm{pH}$ 7.2, and, after being pelleted, these mitochondria were washed in $0.3 \mathrm{M}$-sucrose $/ 2 \mathrm{~mm}$-Tes, $\mathrm{pH} 7.2$, to remove the $\mathrm{Mg}^{2+}$ and EGTA before the measurement of 9-aminoacridine fluorescence. Fluorescence of 9-aminoacridine was measured as described in the Materials and methods section by using protein concentrations of 0.46 (control) and 0.39 (treated) $\mathrm{mg} \cdot \mathrm{ml}^{-1}$.

EDTA $[($ EGTA effect $) /($ EDT A effect $)=0.24$; Fig. $5]$.

It would thus appear as if the relative efficiency of the two chelators in causing a decrease in the fluorescence of 9-aminoacridine in the presence of mitochondria is a good measure of the proportion of $\mathrm{Mg}^{2+}$ and $\mathrm{Ca}^{2+}$ present on the membranes.

In order to see whether NADH oxidation was dependent on $\mathrm{Mg}^{2+}$ or $\mathrm{Ca}^{2+}, \mathrm{NADH}$ oxidation was measured in the presence of $2 \mathrm{mM}$ of either of these cations and increasing concentrations of chelators. The results are shown in Fig. 6. EGTA gives an S-shaped inhibition curve in the presence of $\mathrm{Mg}^{2+}$, which is very similar to the one measured in the presence of $\mathrm{DM}^{2+}$ (Fig. 3). The other three combinations of chelators and cations show 'uninhibited' rates even at $500 \mu \mathrm{M}$-chelator (Fig. 6). In the presence of EGTA, excess $\mathrm{Mg}^{2+}$ is clearly not sufficient to allow NADH oxidation to take place. The fact that $\mathrm{Mg}^{2+}$ gave 'uninhibited' rates in the presence of EDTA could not be solely due to the creation of maximal screening conditions (Fig. 4), since it has already been shown that maximal

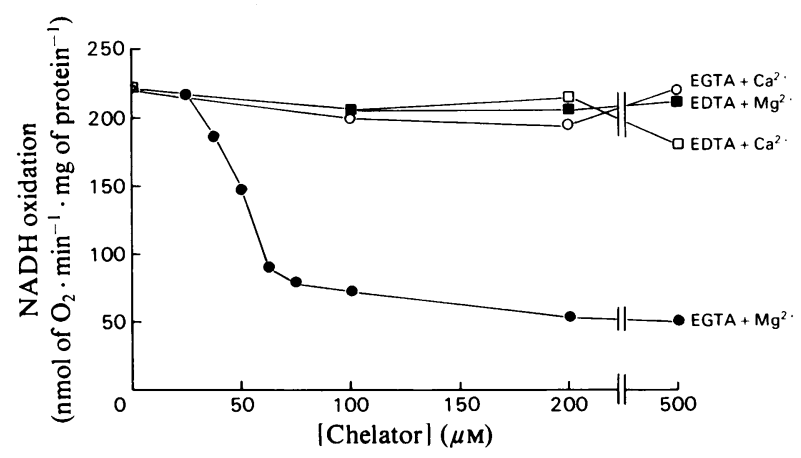

Fig. 6. Effect of chelators on NADH oxidation in the presence of $\mathrm{Ca}^{2+}$ or $\mathrm{Mg}^{2+}$

NADH oxidation was measured as described in the Materials and methods section $(0.44 \mathrm{mg}$ of protein $\cdot \mathrm{ml}^{-1}$ ), except that $2 \mathrm{mM}-\mathrm{CaCl}_{2}$ (open symbols) or $2 \mathrm{mM}-\mathrm{MgCl}_{2}$. (closed symbols) was added together with the main addition of NADH. EGTA (circles) or EDTA (squares) were added to the final concentrations indicated.

screening by $\mathrm{DM}^{2+}$ could not remove inhibition by EGTA or EDTA (Figs. 3 and 4). Therefore it was thought that EDTA would remove $\mathrm{Ca}^{2+}\left(\right.$ and $\left.\mathrm{Mg}^{2+}\right)$ from the membranes and that the addition of excess $\mathrm{Mg}^{2+}$ would displace the $\mathrm{Ca}^{2+}$ from its EDTA complex, allowing it to return to specific sites on the membrane essential for NADH oxidation. The inability of $\mathrm{Mg}^{2+}$ to give 'uninhibited' rates in the presence of EGTA could be due to the lower stability constant of $\mathrm{Mg}^{2+}$ with EGTA (5.3, as opposed to 8.7 with EDTA; Sillén \& Martell, 1964, 1971). This point was pursued further by looking at the ability of a variety of cations with widely varying complexing abilities to reverse the inhibition of NADH oxidation caused by adding a chelator. The results obtained with EGTA are shown in Table 2. In all assays $2 \mathrm{mM}-\mathrm{DM}^{2+}$ was included to ensure maximal charge screening so that observed effects would not be due to differences in screening.

In the absence of EGTA, most of the cations had little or no effect on NADH oxidation, only $\mathrm{La}^{3+}$ and $\mathrm{Cu}^{2+}$ inhibiting strongly. The result with $\mathrm{La}^{3+}$ is a confirmation of previous results (Johnston et al., 1979). EGTA $(200 \mu \mathrm{M})$ inhibited $55 \%$ in the presence of $\mathrm{DM}^{2+}$, which is similar to the amount of inhibition found in Table 1 and in Fig. 3. With the exception of $\mathrm{TEC}^{3+}$, the abilities of cations to reverse this EGTA inhibition closely match the stability constants of their EGTA complexes. It is particularly noteworthy that $150 \mu \mathrm{M}-\mathrm{La}^{3+}$ or $-\mathrm{Cu}^{2+}$, which are shown to be strongly inhibitory alone, reversed the inhibition by $200 \mu \mathrm{M}$-EDTA almost completely. The addition of excess $\mathrm{La}^{3+}$ or $\mathrm{Cu}^{2+}$ ( $2 \mathrm{mM})$ still inhibited strongly. The partial reversal 
Table 2. Reversal of EGTA inhibition of NADH oxidation by a range of cations

The rate of NADH oxidation was measured as described in the Materials and methods section. EGTA was added after the sparker NADH and $30 \mathrm{~s}$ before the main addition of NADH. The salt whose reversal of EGTA inhibition was to be investigated was added $1 \mathrm{~min}$ after the main NADH addition. The results are from two different preparations and the rates and S.D. values are given in the top of the Table. Protein concentrations were 0.43 and $0.48 \mathrm{mg} \cdot \mathrm{ml}^{-1}$. Stability constants are from Sillén \& Martell $(1964,1971)$.

\begin{tabular}{|c|c|c|c|}
\hline \multirow[b]{2}{*}{ Cation } & \multicolumn{2}{|c|}{$\begin{array}{l}\text { NADH oxidation } \\
\text { (nmol of } \mathrm{O}_{2} / \mathrm{min} \text { per } \mathrm{mg} \text { of protein) }\end{array}$} & \multirow{2}{*}{$\begin{array}{l}\text { Stability constant } \\
\text { of cation-EGTA } \\
\text { complex }\end{array}$} \\
\hline & No chelator & $200 \mu \mathrm{M}-\mathrm{EGTA}$ & \\
\hline None & $127 \pm 2(2)$ & $68 \pm 6(2)$ & \\
\hline $2 \mathrm{mM}-\mathrm{CaCl}_{2}$ & $204 \pm 13(2)$ & - & \\
\hline $2 \mathrm{mM}-(\mathrm{DM}) \mathrm{Br}_{2}$ & $186 \pm 14(2)$ & $81 \pm 3(2)$ & \\
\hline $2 \mathrm{mM}-(\mathrm{DM}) \mathrm{Br}_{2}+$ the following & & & \\
\hline $100 \mathrm{~mm}-\mathrm{LiCl}$ & 163 & 69 & 1.2 \\
\hline $100 \mathrm{~mm}-\mathrm{NaCl}$ & 199 & 36 & 1.4 \\
\hline $150 \mu \mathrm{M}-\mathrm{MgCl}_{2}$ & 202 & 54 & 5.3 \\
\hline $2 \mathrm{mM}-\mathrm{MgCl}_{2}$ & - & 41 & 5.3 \\
\hline $150 \mu \mathrm{M}-\mathrm{AgNO}_{3}$ & 139 & 71 & 7.0 \\
\hline $2 \mathrm{mM}^{-\mathrm{AgNO}_{3}}$ & - & 60 & 7.0 \\
\hline $150 \mu \mathrm{M}-\mathrm{SrCl}{ }_{2}$ & 199 & 207 & 8.1 \\
\hline $2 \mathrm{mM}^{-\mathrm{SrCl}_{2}}$ & - & 230 & 8.1 \\
\hline $150 \mu \mathrm{M}-\mathrm{CaCl}_{2}$ & 207 & - & 11.0 \\
\hline $2 \mathrm{mM}-\mathrm{CaCl}_{2}$ & 207 & 230 & 11.0 \\
\hline $150 \mu \mathrm{M}-\mathrm{FeSO}_{4}$ & 151 & 159 & 11.9 \\
\hline $2 \mathrm{mM}^{-\mathrm{FeSO}_{4}}$ & - & $202 \rightarrow 71$ & 11.9 \\
\hline $150 \mu \mathrm{M}-\mathrm{MnCl}_{2}$ & 189 & 176 & 12.2 \\
\hline $2 \mathrm{mM}-\mathrm{MnCl}_{2}$ & - & 89 & 12.2 \\
\hline $150 \mu \mathrm{M}-\mathrm{LaCl}_{3}$ & 26 & 182 & 15.7 \\
\hline $2 \mathrm{~mm}-\mathrm{LaCl}_{3}$ & - & 17 & 15.7 \\
\hline $150 \mu \mathrm{M}-\mathrm{CuCl}{ }_{2}$ & 9 & 142 & 17.7 \\
\hline $2 \mathrm{mM}-\mathrm{CuCl}_{2}$ & - & 0 & 17.7 \\
\hline $100 \mu \mathrm{M}-(\mathrm{TEC}) \mathrm{Cl}_{3}$ & - & 136 & See the text \\
\hline
\end{tabular}

caused by TEC $^{3+}$ is difficult to understand, since $\mathrm{TEC}^{3+}$ contains a $\mathrm{Co}^{3+}$ ion, where all co-ordination sites are occupied by ethylenediamine, and $\mathrm{TEC}^{3+}$, therefore, should not complex EGTA. It could be explained, however, by assuming an exchange between the ethylenediamine and the EGTA at the $\mathrm{Co}^{3+}$-co-ordination sites. The released ethylenediamine complexes $\mathrm{Ca}^{2+}$ weakly and the net result would be an increase in free $\mathrm{Ca}^{2+}$. A small amount of free $\mathrm{Co}^{3+}$ in the (TEC)Cl ${ }_{3}$ solution is also possible.

The reversal of EDTA-inhibited rates of NADH oxidation by cations (results not shown) is comparable with that obtained with EGTA, including a partial reversal by $\mathrm{TEC}^{3+}$. The only exception is that $\mathrm{Mg}^{2+}$ can reverse EDTA inhibition, as shown in Fig. 6. Again this is in perfect agreement with the known stability constants of the complexes between the cations and EDTA (Sillén \& Martell, 1964, 1971).

Finally, it should be noted that an effect by chelators on the fluorescence of 9-aminoacridine (Figs. 4 and 5) is observed at low concentrations $(10 \mu \mathrm{M})$, whereas no effect is observed on NADH oxidation below $30 \mu \mathrm{M}$ (Figs. 3 and 6). In Table 3,
Table 3. Concentration of chelator at which halfmaximal effect is observed on $N A D H$ oxidation and 9-aminoacridine (9-AA) fluorescence

The data for the effect on NADH oxidation are from Figs. 3 and 6 . The fluorescence of 9-aminoacridine was measured on the same three preparations.

$\underset{(\mu \mathrm{M})}{[\mathrm{EGTA}]} \underset{(\mu \mathrm{M})}{[\mathrm{EDTA}]}$

Inhibition of NADH oxidation
(a) No cation added
(b) $+2 \mathrm{mM}-(\mathrm{DM}) \mathrm{Br}_{2}$
(c) $+2 \mathrm{mM}-\mathrm{MgCl}_{2}$
$\begin{array}{ll}78 & 69\end{array}$
$70 \quad 66$
52

Quenching of 9-AA fluorescence

$35 \pm 8(3) \quad 29 \pm 6(3)$

data on NADH oxidation and the fluorescence of 9-aminoacridine for the same preparations are compared. The effect of a chelator is expressed as the concentration needed to give half-maximal inhibition of NADH oxidation (from Figs. 3 and 6) or half-maximal quenching of the fluorescence of 9-aminoacridine. It is clear that the first bivalent 
cations that are removed from the membranes by low concentrations of chelators influence the fluorescence of 9-aminoacridine, but have no involvement in NADH oxidation (Table 3).

\section{Discussion}

In a previous paper the oxidation of exogenous $\mathrm{NADH}$ by Jerusalem-artichoke mitochondria isolated in a low-cation medium was shown to be stimulated in an unspecific manner by cations, the efficiency being determined only by the valency of the cation (Johnston et al., 1979). The evidence given in the present paper shows that Jerusalemartichoke mitochondria are isolated with about equal amounts of $\mathrm{Ca}^{2+}$ and $\mathrm{Mg}^{2+}$ associated with the membranes (Figs. 4 and 5) and that an inhibition of NADH oxidation is observed when these bivalent cations are removed by chelators, even in the presence of $2 \mathrm{mM}^{-D^{2+}}$ to give maximal screening of fixed membrane charges (Figs. 3, 4 and 5). This inhibition can be shown to be specifically due to the removal of $\mathrm{Ca}^{2+}$, since an inhibition caused by EGTA is observed in the presence of excess $\mathrm{Mg}^{2+}$ (Fig. 6). The fact that maximal activity is observed in the presence of EDTA and excess $\mathrm{Mg}^{2+}$ (Fig. 6) is due to the displacement of $\mathrm{Ca}^{2+}$ from its EDTA complex by $\mathrm{Mg}^{2+}$. This effect is demonstrated with a variety of cations of different complexing ability (Table 2). Thus the oxidation of exogenous NADH by Jerusalem-artichoke mitochondria appears to have a specific requirement for $\mathrm{Ca}^{2+}\left(\mathrm{Sr}^{2+}\right.$ can possibly substitute).

It is possible that removal of the $\mathrm{Mg}^{2+}$ from the membranes has some effect on NADH oxidation. In fact Fig. 3 quite clearly shows that EDTA inhibits significantly better than EGTA both in the lowcation medium and in the presence of $\mathrm{DM}^{2+}$. This must be due to $\mathrm{Mg}^{2+}$ being removed from binding sites on which $\mathrm{DM}^{2+}$ cannot substitute. From Fig. 5 we know that such sites apparently exist, since chelators have a small but significant effect on the fluorescence of 9-aminoacridine even in the presence of $\mathrm{DM}^{2+}$.

Not all the $\mathrm{Ca}^{2+}$ on the membranes is equally important for the activity of the NADH dehydrogenase. The results presented in Table 3 and Figs. 3 and 6 show that some $\mathrm{Ca}^{2+}$ can be removed by chelators without any effect on the NADH oxidation. Since the outer membrane is permeable to all molecules employed in the present study (Pfaff $e t$ al., 1968) and since the mitochondrial inner membrane is not thought to be permeable to EDTA or EGTA (Imedidze et al., 1978; Reed \& Bygrave, 1974; Wehrle et al., 1976), addition of chelators in the presence of 9-aminoacridine will yield information on the two surfaces of the outer membrane as well as on the outer surface of the inner membrane, where the NADH dehydrogenase appears to be located (Palmer \& Passam, 1971). It is very likely that a portion of the bivalent cations that can be seen by the 9-aminoacridine technique (Figs. 4 and 5) are located on the outer membrane. The removal of these would be expected to have rather little effect on NADH oxidation, and this could account for the observed lack of inhibition by low concentrations of chelators (Figs. 3 and 6).

Having shown that $\mathrm{Ca}^{2+}$ is required for the oxidation of exogenous NADH, the time-dependencies observed in Figs. 1 and 2 and the effect of sequence of addition of chelator and main NADH (Table 1) take on special significance, since they provide indirect evidence on the more detailed mechanism of the dehydrogenase.

The fact that chelators inhibited more in the low-cation medium when added before the NADH than after (Table 1 and Fig. 2) indicates that the oxidation of NADH somehow makes $\mathrm{Ca}^{2+}$ less accessible to the chelators. This may be due to a conformational change of the dehydrogenase that locks $\mathrm{Ca}^{2+}$ into the active site. To remove the $\mathrm{Ca}^{2+}$ after it has been locked into place requires the close approach of the chelator. This is apparent from Fig. 2, which shows that EGTA and EDTA (both negatively charged at $\mathrm{pH}$ 7.2) when added after NADH inhibit more rapidly under screening conditions $\left(+\mathrm{DM}^{2+}\right.$, Fig. $\left.2 a\right)$ than in the low-cation medium (Fig. $2 b$ ), where the chelators would be repulsed by the relatively unscreened charges.

The lag before maximal linear rates of NADH oxidation were reached, observed in Fig. 1, could represent the 'locking-into-place' phase. As a result of the oxidation of NADH, $\mathrm{Ca}^{2+}$ is mobilized from adjacent sites on the outer surface of the inner membrane or from the matrix by a translocation process and locked into the active site of the dehydrogenase in a time- and respiration-dependent manner. The function of the sparker addition of $\mathrm{NADH}$ in decreasing the duration of the lag phase could then be to induce this conformational change in the dehydrogenase enzyme.

In connection with the above speculation, it is noteworthy that the mitochondria that were relatively depleted of $\mathrm{Ca}^{2+}$ after an EGTA $+\mathrm{Mg}^{2+}$ wash (Fig. 5) showed significantly longer lags before linear rates were attained than did the controls (I. M. Møller, unpublished work). This could be due to the mitochondria having to mobilize $\mathrm{Ca}^{2+}$ from a more distant or more respiration-demanding pool.

Lehninger et al. (1978) suggested that $\mathrm{Ca}^{2+}$ movement across the inner membrane of mammalian mitochondria is regulated by the reduction level of the pyridine-nucleotide pool inside the mitochondria. $\mathrm{Ca}^{2+}$ is taken up when the pyridine nucleotides are relatively reduced and a $\mathrm{Ca}^{2+}$ efflux is observed under conditions where the pyridine 
nucleotide pool is relatively oxidized. Future work will show whether the involvement of $\mathrm{Ca}^{2+}$ in the oxidation of exogenous NADH in plant mitochondria fits a similar model.

We thank Mrs. Jill Farmer for expert technical assistance. I. M. M. is a recipient of a NATO Science Fellowship and grants nos. 511-15019 and 511-20033 from the Danish Natural Science Research Council. This study was supported by grants from the Science Research Council, The Royal Society and the Central Research Fund, University of London.

\section{References}

Coleman, J. O. D. \& Palmer, J. M. (1971) FEBS Lett. 17, 203-208

Cowley, R. C. \& Palmer, J. M. (1978) Plant Sci. Lett. 11, 345-350

Earnshaw, M. J. (1975) FEBS Lett. 59, 109-112

Imedidze, E. A., Drobinskaya, I. E., Kerimov, T. M., Ruuge, E. K. \& Kozlov, I. A. (1978) FEBS Lett. 96, 115-119
Johnston, S. P., Møller, I. M. \& Palmer, J. M. (1979) FEBS Lett. 108, 28-32

Lehninger, A. L., Vercesi, A. \& Bababunmi, E. A. (1978) Proc. Natl. Acad. Sci. U.S.A. 75, 1690-1694

Lowry, O. H., Rosebrough, N. J., Farr, A. L. \& Randall, R. J. (1951) J. Biol. Chem. 193, 265-275

Miller, R. J., Dumford, S. W., Koeppe, D. E. \& Hanson, J. B. (1970) Plant Physiol. 45, 649-653

Møller, I. M., Chow, W.-S., Palmer, J. M. \& Barber, J. (1980) Biochem. J. 193, 37-46

Palmer, J. M. \& Kirk, B. I. (1974) Biochem. J. 140, 79-86

Palmer, J. M. \& Passam, H. C. (1971) Biochem. J. 122, $16 \mathrm{P}-17 \mathrm{P}$

Pfaff, E., Klingenberg, M., Ritt, E. \& Vogell, W. (1968) Eur. J. Biochem. 5, 222-232

Reed, K. C. \& Bygrave, F. L. (1974) Biochem. J. 138, 239-252

Sillén, L. G. \& Martell, A. E. (1964) Chem. Soc. Spec. Publ. no. 17

Sillén, L. G. \& Martell, A. E. (1971) Chem. Soc. Spec. Publ. no. 25

Wehrle, J. P., Jurkowitz, M., Scott, K. M. \& Brierley, G. P. (1976) Arch. Biochem. Biophys. 174, 312323 